\title{
Physical and mental health impacts of COVID-19 on healthcare workers: a scoping review
}

Natasha Shaukat ${ }^{1,2^{*}}$, Daniyal Mansoor Ali $^{2}$ and Junaid Razzak ${ }^{2,3}$

\begin{abstract}
Background: Coronavirus disease (COVID-19) pandemic has spread to 198 countries, with approximately 2.4 million confirmed cases and 150,000 deaths globally as of April 18. Frontline healthcare workers (HCWs) face a substantially higher risk of infection and death due to excessive COVID-19 exposure. This review aimed at summarizing the evidence of the physical and mental health impacts of COVID-19 pandemic on health-care workers (HCWs).
\end{abstract}

Methods: We used the Arksey O'Malley framework to conduct a scoping review. A systematic literature search was conducted using two databases: PubMed and Google Scholar. We found 154 studies, and out of which 10 met our criteria. We collected information on the date of publication, first author's country, the title of the article, study design, study population, intervention and outcome, and key findings, and divided all research articles into two domains: physical and mental health impact.

Results: We reviewed a total of 154 articles from PubMed (126) and Google Scholar (28), of which 58 were found to be duplicate articles and were excluded. Of the remaining 96 articles, 82 were excluded after screening for eligibility, and 4 articles did not have available full texts. Ten full-text articles were reviewed and included in this study.

Our findings identified the following risk factors for COVID-19-related health impact: working in a high-risk department, diagnosed family member, inadequate hand hygiene, suboptimal hand hygiene before and after contact with patients, improper PPE use, close contact with patients ( $\geq 12$ times/day), long daily contact hours ( $\geq$ $15 \mathrm{~h}$ ), and unprotected exposure. The most common symptoms identified amongst HCWs were fever (85\%), cough (70\%), and weakness (70\%). Prolonged PPE usage led to cutaneous manifestations and skin damage (97\%), with the nasal bridge (83\%) most commonly affected site. HCWs experienced high levels of depression, anxiety, insomnia, and distress. Female HCWs and nurses were disproportionately affected.

Conclusion: The frontline healthcare workers are at risk of physical and mental consequences directly as the result of providing care to patients with COVID-19. Even though there are few intervention studies, early data suggest implementation strategies to reduce the chances of infections, shorter shift lengths, and mechanisms for mental health support could reduce the morbidity and mortality amongst HCWs.

Keywords: COVID-19, Healthcare workers, Health impacts, Risk factors, Occupational health

\footnotetext{
* Correspondence: natasha.shaukat@aku.edu

'Department of Community Health Sciences, Aga Khan University, Stadium

Road, P.O. Box-3500, Karachi, Pakistan

${ }^{2}$ Centre of Excellence Trauma and Emergencies, Aga Khan University, Karachi,

Pakistan

Full list of author information is available at the end of the article
}

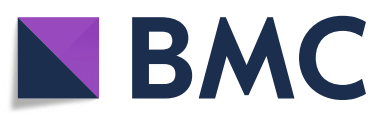

(c) The Author(s). 2020 Open Access This article is licensed under a Creative Commons Attribution 4.0 International License, which permits use, sharing, adaptation, distribution and reproduction in any medium or format, as long as you give appropriate credit to the original author(s) and the source, provide a link to the Creative Commons licence, and indicate if changes were made. The images or other third party material in this article are included in the article's Creative Commons licence, unless indicated otherwise in a credit line to the material. If material is not included in the article's Creative Commons licence and your intended use is not permitted by statutory regulation or exceeds the permitted use, you will need to obtain permission directly from the copyright holder. To view a copy of this licence, visit http://creativecommons.org/licenses/by/4.0/. The Creative Commons Public Domain Dedication waiver (http://creativecommons.org/publicdomain/zero/1.0/) applies to the data made available in this article, unless otherwise stated in a credit line to the data. 


\section{Background}

Coronavirus disease 2019 (COVID-19) was first identified in Wuhan City in December 2019, after which, the disease spread throughout Hubei Province and other parts of China [1,2]. After causing significant morbidity and mortality in China, by February 2020, COVID-19 had spread to numerous other countries, including the USA, Italy, Spain, Germany, France, and Iran [3-5]. As of April 18, COVID-19 has spread to 198 countries, infecting 2.4 million people and causing 150,000 deaths across the world and is therefore considered a global pandemic [6-8].

Healthcare workers (HCWs) are amongst the high-risk group to acquire this infection [9-11]. China reported infection in $3387 \mathrm{HCWs}$, while $22 \mathrm{HCWs}(0.6 \%)$ died due to the illness $[9,12]$. Similarly, Italy $(20 \%)$, Spain (14\%), and France (over 50 deaths amongst HCWs) reported high rates of HCW infection [10, 13, 14].

Given the high burden, there is a growing demand and focus on protecting HCWs across the world through provision of personal protective equipment (PPE), training, addressing fatigue, and countering the psychosocial consequences [15-21].

The literature on the health consequences of HCWs providing care to COVID-19 patients is proliferating, and no review is available to guide practitioners and leaders on the efficacy of various interventions. This scoping review aims to summarize the evidence of the physical and mental health impacts of COVID-19 pandemic on healthcare workers.

\section{Methods}

\section{Study design}

We used the methodological framework by Arksey and O'Malley to conduct the scoping review [22]. The five steps followed were identifying a clear research question and objective; identifying relevant articles; selection of articles, data extraction; and charting of data, organizing, summarizing, analyzing, and reporting of data [22]. The primary research question guiding this review is "What are the physical and mental health effects of managing patients with COVID-19 on the frontline health-care workers?"

\section{Literature search strategies}

We searched PubMed or Medical Literature Analysis and Retrieval System Online (MEDLINE), and Google Scholar for relevant articles from January to March 2020. Medical subject headings $(\mathrm{MeSH})$ were searched using Boolean operators "OR/AND". The search terms were: ("2019-nCoV" OR "coronavirus" OR "COVID-19" OR "nCoV)" AND ("health-care workers") AND ("health impacts" OR "physical health" OR "mental health").

\section{Eligibility criteria}

We included studies assessing the impact of COVID-19 on the health of HCWs and were published in the English language and published from January to March 2020. Healthcare workers included all clinical staff, including doctors, nurses, paramedics, and technicians. Editorials, commentaries, and non-English articles were excluded.

\section{Identification and selection of studies}

Two researchers (NS and DMA) independently searched through the literature. The two sets of literature were then compared, and duplicate articles were removed. Figure 1 presents a Preferred Reporting Items for Systematic Reviews and Meta-Analyses (PRISMA) flow diagram showing the process of searching and selecting the research articles.

\section{Data extraction from included studies}

After the selection of the articles, we extracted and recorded data in a data extraction form in an Excel spreadsheet. The domains in the data extraction form were date of publication, the title of the article, name of the journal, study design, study setting and population, intervention, and outcome reported and key findings.

\section{Summarizing the findings}

We summarized our findings into the following research domains: mental health impacts and physical health impacts.

\section{Results}

\section{Studies' characteristics}

A total of 154 articles were retrieved from PubMed (126 articles) and Google Scholar (28 articles). Fifty-eight duplicate articles were excluded. Out of the remaining 96 articles, 82 articles were either not related to the impact of COVID-19 on healthcare workers, were editorials or commentaries, or were written in a language other than English, and no English translation was available and therefore were excluded. Among the remaining 14 articles, 4 articles did not have available full texts. Ten fulltext articles were reviewed and included in this study. Out of the ten studies included, two were written in Chinese but had English translations available.

\section{Research domains}

Among the 10 studies included in this review, 5 studies assessed mental health impacts, and 5 studies assessed the physical health impacts of COVID-19 on healthcare workers. The methodological characteristics of these studies are summarized in Table 1 . Six were crosssectional, two were interventions, one was a retrospective cohort, and one was a case series. The study 


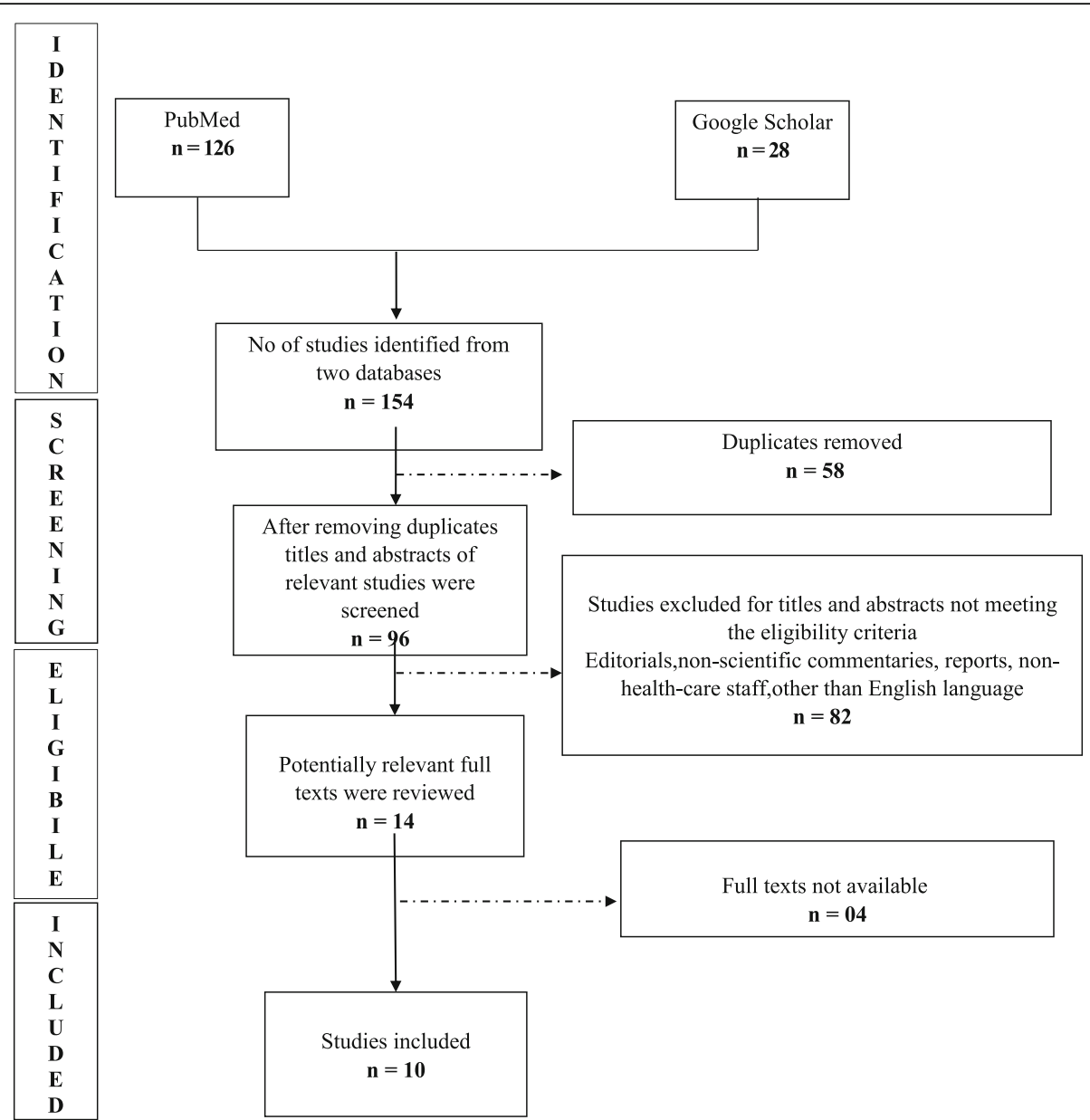

Fig. 1 PRISMA flow diagram for database search of studies

population comprised both male and female, including frontline physicians, nurses, and specialist staff. Most of the studies (90\%) were from scholars in the Peoples Republic of China (PRC), while one was from scholars based in Singapore.

The findings related to mental health and physical health impact of COVID-19 on healthcare workers from the included articles are summarized in Table 2.

\section{Mental health impacts}

Five articles discussed mental health impact on healthcare providers. In one study, out of 230 healthcare workers who responded to the mental health assessment scales, 53 (23.04\%) had psychosocial problems. Among these 53 medical staff, more females $(48(90.57 \%))$ than males $(5(9.43 \%))$, and more nurses $(43(81.13 \%))$ than physicians $(10(18.9 \%))$ suffered from mental health issues due to the infectious outbreak [23]. The psychological impact on healthcare workers included the following conditions: overall anxiety (23-44\%), severe anxiety $(2.17 \%)$, moderate anxiety $(4.78 \%)$, mild anxiety (16.09\%), stress disorder (27.4-71\%), depression (50.4\%), and insomnia (34.0\%) [23, 24]. Anxiety in females was higher than in males ( $25.67 \%$ vs. $11.63 \%)$, nurses higher than doctors (26.88\% vs. $14.29 \%)$ [23]. Frontline healthcare workers engaged in direct COVID-19 patient care

Table 1 Methodological characteristics of COVID-19 research articles

\begin{tabular}{lll}
\hline Research domain & Study design $n(\%)$ & Study population $n$ (\%) \\
\hline Mental health impact & Cross-sectional study 3 (30\%) & Healthcare workers (nurses and physicians) 4143 \\
Interventional study 2 (20\%) & \\
Physical health impact & Cross-sectional study 3 (30\%) & Healthcare workers (nurses, frontline physicians and \\
& Retrospective cohort study 1 (10\%) & ICU medical staff) 1267 \\
\hline
\end{tabular}




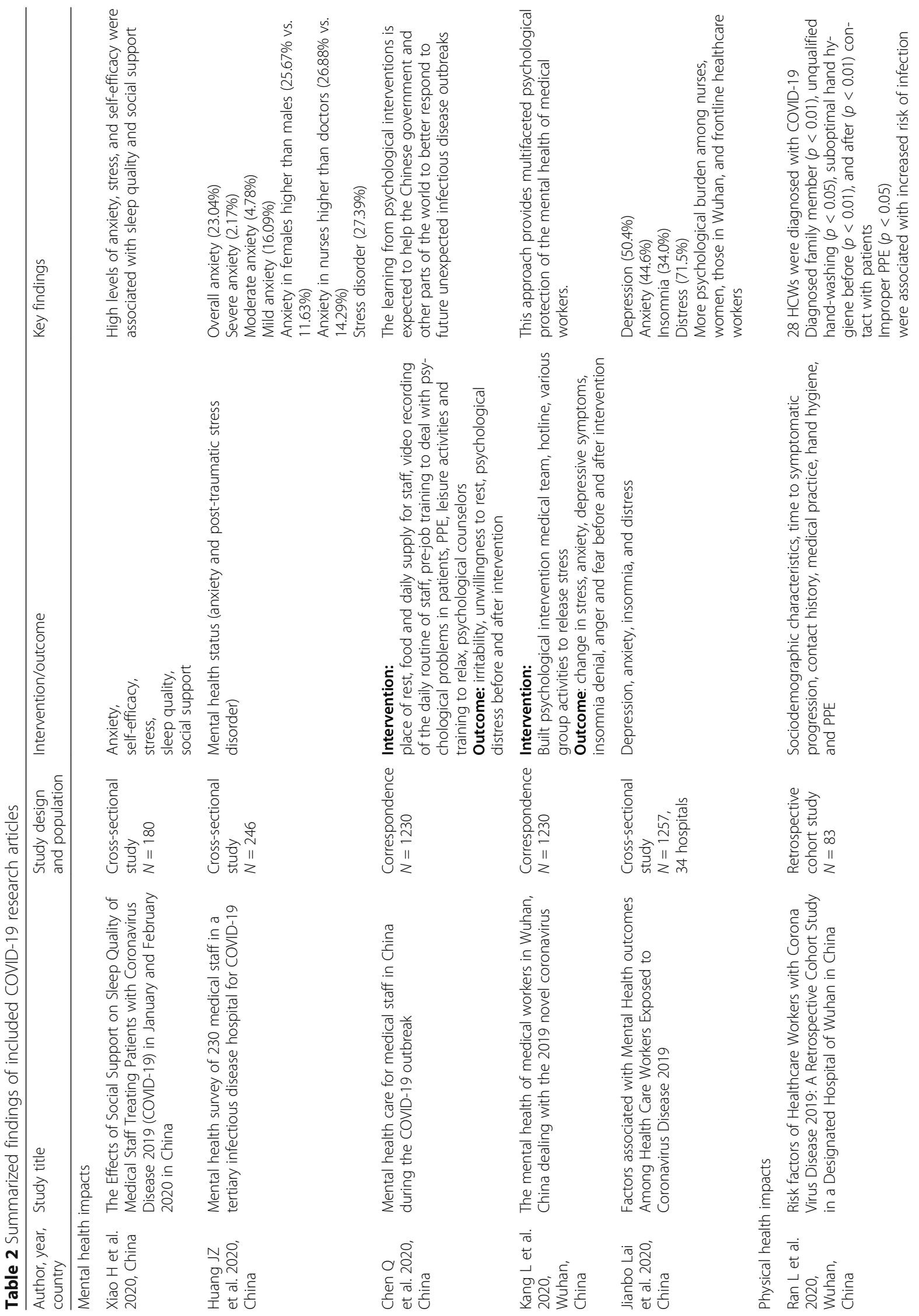




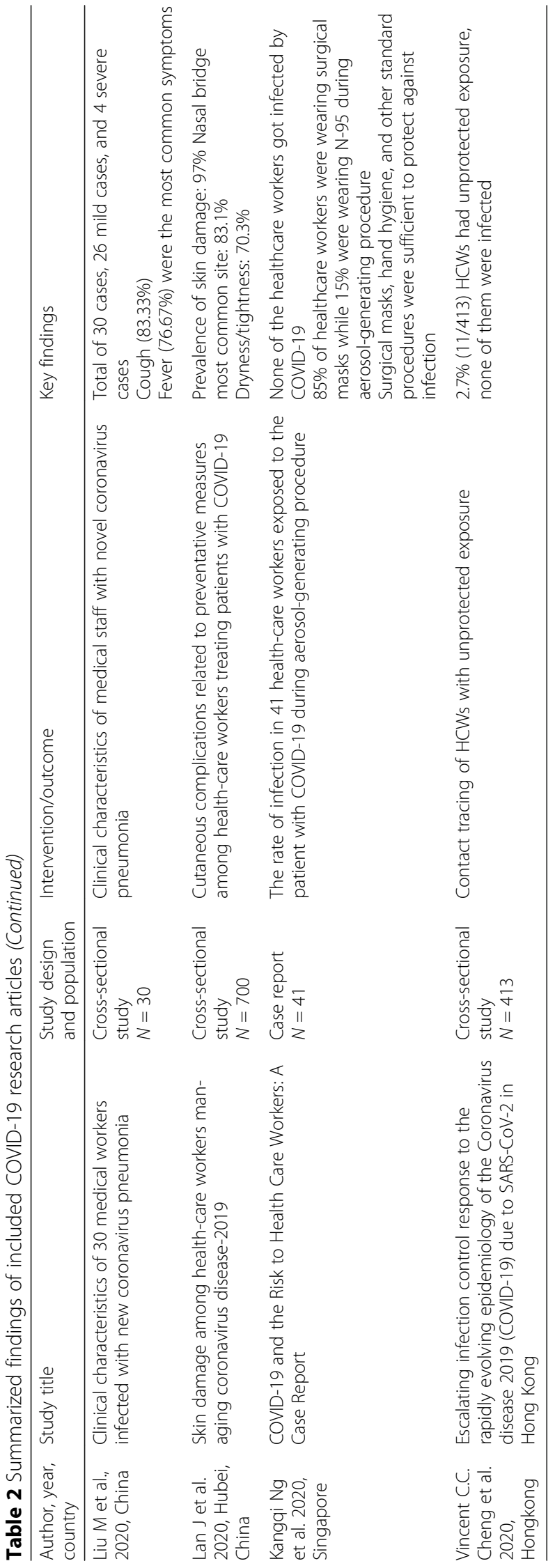


were at higher risk of depression (OR 1.52; 95\% CI $1.11-2.09)$, anxiety (OR,1.57; 95\% CI 1.22-2.02), insomnia (OR 2.97; 95\% CI 1.92-4.60), and distress (OR 1.60; 95\% CI 1.25-2.04) [24].

The tools used in these studies included Self-Rating Anxiety Scale [23, 25], Generalized Anxiety Disorder Scale [24], General Self-Efficacy Scale [25], Stanford Acute Stress Reaction Questionnaire [25], Pittsburgh Sleep Quality Index [25], Insomnia Severity Index [24], Social Support Rate Scale [25], Post-Traumatic Stress Disorder Self-Rating Scale [23], and Impact of Event Scale [24].

\section{Physical health impacts \\ COVID-19 infection transmission and mortality among healthcare providers}

Early studies from the Peoples Republic of China (PRC) demonstrate that HCWs are more susceptible to COVID-19. Studies amongst HCWs in PRC showed that COVID-19 risk was linked with working in high-risk department such as infectious disease and pulmonology $(\mathrm{RR}=2.13,95 \%$ CI 1.45-3.95), diagnosed family member $(\mathrm{RR}=2.76,95 \% \mathrm{CI} 2.02-3.77)$, inadequate hand hygiene $(R R=2.64,95 \%$ CI 1.04-6.71), suboptimal hand hygiene before and after contact with patients $(\mathrm{RR}=$ 2.43, 95\% CI 1.34-4.39), improper PPE ( $\mathrm{RR}=2.82,95 \%$ CI 1.11-7.18), close contact with patients (12 times/day), long daily contact hours ( $\geq 15 \mathrm{~h}$ ), and unprotected exposure. Common symptoms were fever (85\%), cough (80\%), weakness $(70 \%)$, chest distress $(7 \%)$, hemoptysis (7\%), headache (7\%), and diarrhea (7\%) [17, 26, 27]. Similarly, another study showed that COVID-19 infected 30 medical staff, including 20 doctors and 8 nurses in a hospital. Of these, 26 had mild, and 4 had a severe infection, and all of them had exposure to the virus [27]. A case series from Singapore recorded outcomes of 41 HCWs who were exposed to a patient with COVID-19 pneumonia before diagnosis of COVID in this patient. None of the $41 \mathrm{HCWs}$ developed COVID-19. All the HCWs were wearing surgical and N-95 masks at the time of exposure [28].

\section{Cutaneous manifestations}

Prevention against the viral illness meant that healthcare workers had to wear personal protective equipment (PPE) for a prolonged period. A cross-sectional study demonstrated skin damage in $97 \%$ of the medical staff, with the nasal bridge (83.1\%), being the most commonly affected site. The most common presenting symptom was dryness or tightness and desquamation (70.3\%), and these manifestations were associated with more than $6 \mathrm{~h}$ of continuous PPE use and more than 10 times/day hand hygiene [29].

\section{Discussion}

This review collates evidence on the health impacts of COVID-19 on HCWs. Our findings suggest HCWs are susceptible to various health consequences due to the COVID-19 pandemic. For those with COVID-19 infections, the most common symptoms were fever and cough, which were similar to those seen in the community. Several risk factors were identified; long duty hours, working in the high-risk department, lack of PPE, diagnosed family member, unqualified hand-washing, and improper infection control. Furthermore, prolonged PPE usage led to skin damage, with the nasal bridge being the most common site. Battling COVID-19 on the frontline makes HCWs vulnerable to psychological distress. Finding shows high levels of depression, stress, anxiety, distress, anger, fear, insomnia, and post-traumatic stress disorder in the HCWs. Females and nurses were disproportionately affected more from mental health consequences. Frontline female nurses work in close contact with patients for longer working hours, which may result in fatigue, stress, and anxiety. However, this finding warrants for further research to better prepare for the future.

Worldwide, COVID-19 has affected large numbers of frontline HCWs. As of March 2020, COVID-19 has infected more than $3000 \mathrm{HCWs}$ in China only [30]. A similar situation was witnessed in previous outbreaks of Ebola virus disease (EVD), Middle East respiratory syndrome (MERS), and severe acute respiratory syndrome (SARS) [31-35]. Figures from Sierra Leone, Liberia, and Guinea showed approximately $6-8 \%$ of Ebola infection amongst the HCWs [35], SARS infected approximately $1000 \mathrm{HCWs}$, and $1.4 \%$ deaths occurred in China only [36]. Early COVID-19 studies indicate a worrisome situation of morbidity and mortality [16, 20]. The fact that healthcare workers are at increased risk of infection by COVID-19 will further exacerbate the existing shortage of skilled workforce, as most health systems and EDs are running at their full capacities [18, 20,30,37].

During outbreaks, the HCWs experience considerable stress. In a Chinese study during the Ebola outbreak, HCWs reported extreme somatization, depression, anxiety, and obsession-compulsion [38]. During the MERS outbreak, a Saudi study reported almost two-third of HCWs felt at risk of getting infected with MERS CoV and felt unsafe at work [39]. These findings are consistent with previous SARS situations in which HCWs reported high levels of fear of contagion and infecting family members, emotional disturbance, uncertainty, and stigmatization [40, 41]. Risk factors for mental health include overwhelming situations, social disruption of daily life, feeling vulnerable, at risk of getting infected, fear of transmitting the disease to families, and loved ones [11]. Previous outbreaks showed that HCWs suffer 
significant stress, and a similar outcome is expected in COVID-19.

One of the major challenges faced in controlling this pandemic is the extreme shortage of PPEs [18]. A highly infectious pandemic challenges already compromised health systems with resultant shortages in supplies and PPEs. For instance, during the Ebola outbreak, many countries faced PPE shortages [35, 42]. In a pandemic, ensuring emergency medical supplies is pertinent to national public health emergency response systems [18]. Therefore, it is pertinent to establish an emergency reserve medical supplies program to ensure the provision of supplies based on needs, type, quality, and quantity.

Pandemics exert significant psychological impacts on HCWs, highlighting the need for appropriate psychological support, interventions, and staff support measures. COVID-19-specific psychological interventions for medical staff in China included psychological intervention support teams, psychological counselling, availability of helpline, establishment of shift systems in hospitals, online platforms for medical assistance, incentives, providing adequate breaks and time offs, providing a place to rest and sleep, leisure activities such as yoga, meditation and exercise, and motivational sessions $[15,16]$. Protecting the well-being of HCWs, through appropriate measures is a crucial tool in national emergency public health response to fighting the outbreaks. If timely measures are not taken, although the disease will subside eventually, a new surge of patients suffering from psychological morbidity will emerge.

\section{Strengths and limitations of the study}

The scoping review applied systematic and vigorous search strategy as per the study objective. The study presents a summary the recent scientific evidence and could strengthen the response for the current and future outbreaks. Given the rapidity of the pandemic, studies present here have a relatively short follow-up period. Also, our review included only studies published in the English language and may have missed findings published in other languages. The incidence of health impacts of COVID-19 on HCWs are not documented due to methodological limitations of studies, especially difficulty in finding the actual denominator data. Lastly, interventional studies are relatively scarce.

\section{Conclusion}

HCWs are at risk for developing physical and mental health consequences due to their role in providing care to patients with COVID-19. Implementation of the following strategies may help reduce the burden of health consequences: the adequate provision and training on the use of personal protective equipment, strict infection control practices, shorter shift length, and provision of mental health and support services.

\section{Abbreviations}

COVID-19: Corona virus disease; HCWs: Healthcare workers; PPE: Personal protective equipment; PRISMA: Preferred Reporting Items for Systematic Reviews and Meta-Analyses; EVD: Ebola virus disease; MERS: Middle East respiratory syndrome; SARS: Severe acute respiratory syndrome

\section{Acknowledgements}

We thank all the frontline healthcare heroes who are busy risking their lives in battling this pandemic.

\section{Authors' contributions}

NS and DMA contributed in the study design, data collection, data analysis, data interpretation, and writing of the manuscript. JR contributed in the writing of the manuscript and overall supervision. JR approved the final manuscript. All authors read and approved the final manuscript.

\section{Funding}

None

\section{Availability of data and materials}

The data that support the findings of this study are available from the corresponding author upon reasonable request.

Ethics approval and consent to participate

Not applicable

\section{Consent for publication}

Not applicable

\section{Competing interests}

The authors declare that they have no competing interests.

\section{Author details}

${ }^{1}$ Department of Community Health Sciences, Aga Khan University, Stadium Road, P.O. Box-3500, Karachi, Pakistan. ${ }^{2}$ Centre of Excellence Trauma and Emergencies, Aga Khan University, Karachi, Pakistan. ${ }^{3}$ Centre for Global Emergency Care, Department of Emergency Medicine, Johns Hopkins University School of Medicine, Baltimore, USA.

Received: 29 April 2020 Accepted: 6 July 2020

Published online: 20 July 2020

\section{References}

1. Information for Healthcare Professionals: COVID-19 | CDC. https://www.cdc. gov/coronavirus/2019-nCoV/hcp/index.html. Accessed 27 Mar 2020.

2. Technical guidance. https://www.who.int/emergencies/diseases/novelcoronavirus-2019/technical-guidance. Accessed 27 Mar 2020.

3. Holshue ML, DeBolt C, Lindquist S, Lofy KH, Wiesman J, Bruce H, et al. First case of 2019 novel coronavirus in the United States. N Engl J Med. 2020; 382(10):929-36. https://doi.org/10.1056/NEJMoa2001191.

4. Rothan HA, Byrareddy SN. The epidemiology and pathogenesis of coronavirus disease (COVID-19) outbreak. Journal of Autoimmun. Academic Press; 2020. p. 102433.

5. Bassetti M, Vena A, Giacobbe DR. The novel Chinese coronavirus (2019nCoV) infections: Challenges for fighting the storm. Eur J Clin Invest. 2020; 50(3):e13209. https://doi.org/10.1111/eci.13209.

6. Situation reports. https://www.who.int/emergencies/diseases/novelcoronavirus-2019/situation-reports. Accessed 27 Mar 2020.

7. Dong E, Du H, Gardner L. An interactive web-based dashboard to track COVID-19 in real time. Lancet Infect Dis. 2020. https://doi.org/10.1016/ S1473-3099(20)30120-1.

8. Situation update worldwide, as of 28 March 2020. https://www.ecdc.europa. eu/en/geographical-distribution-2019-ncov-cases.

9. Lin M, Beliavsky A, Katz K, Powis JE, Ng W, Williams V, et al. What can early Canadian experience screening for COVID-19 teach us about how to prepare for a pandemic? Can Med Assoc J. 2020;192(12):E314-8. https://doi. org/10.1503/cmaj.200305.

10. Virus Knocks Thousands of Health Workers Out of Action in Europe. https:// www.nytimes.com/2020/03/24/world/europe/coronavirus-europe-covid-19. html. Accessed 29 Mar 2020. 
11. Koh D. Occupational risks for COVID-19 infection. Occup Med (Lond). 2020; 70(1):3-5.

12. Wang J, Zhou M, Liu F. Reasons for healthcare workers becoming infected with novel coronavirus disease 2019 (COVID-19) in China. J Hosp infect. 2020. https://doi.org/10.1016/j.jhin.2020.03.002.

13. ICN tells BBC World News viewers: Rising rate in COVID-19 infection amongst health workers requires urgent action | ICN - International Council of Nurses. https://www.icn.ch/news/icn-tells-bbc-world-news-viewers-risingrate-covid-19-infection-amongst-health-workers. Accessed 29 Mar 2020.

14. Lancet T. COVID-19: protecting health-care workers. Lancet. 2020;395(10228): 922. https://doi.org/10.1016/S0140-6736(20)30644-9.

15. Chen Q, Liang M, Li Y, Guo J, Fei D, Wang L, et al. Mental health care for medical staff in China during the COVID-19 outbreak. Lancet Psychiatry, 2020;7(4):e15-6.

16. Kang L, Li Y, Hu S, Chen M, Yang C, Yang BX, et al. The mental health of medical workers in Wuhan, China dealing with the 2019 novel coronavirus. Lancet Psychiatry. 2020;7(3):e14.

17. Ran $L$, Chen $X$, Wang $Y$, Wu W, Zhang $L$, Tan $X$. Risk factors of healthcare workers with corona virus disease 2019: A Retrospective Cohort Study in a Designated Hospital of Wuhan in China. Clin Infect Dis. 2020. https://doi. org/10.1093/cid/ciaa287.

18. Wang X, Zhang X, He J. Challenges to the system of reserve medical supplies for public health emergencies: reflections on the outbreak of the severe acute respiratory syndrome coronavirus 2 (SARS-CoV-2) epidemic in China. Biosci Trends. 2020;14(1):3-8.

19. Cascella M, Rajnik M, Cuomo A, Dulebohn SC, di Napoli R. Features, evaluation and treatment coronavirus (COVID-19). StatPearls Publishing. 2020;20.

20. Cavallo JJ, Donoho DA, Forman HP. Hospital capacity and operations in the coronavirus disease 2019 (COVID-19) pandemic - planning for the nth patient. JAMA Health Forum. 2020;1(3):-e200345.

21. Legido-Quigley H, Mateos-García JT, Campos VR, Gea-Sánchez M, Muntaner C, McKee M. The resilience of the Spanish health system against the COVID19 pandemic. The Lancet Public Health. 2020;2667(20):19-20.

22. Arksey H, O'Malley L. Scoping studies: Towards a methodological framework. Int J Soc Res Methodol. 2005;8(1):19-32.

23. Huang JZ, Han MF, Luo TD, Ren AK, Zhou XP. Mental health survey of 230 medical staff in a tertiary infectious disease hospital for COVID-19. Chin J Ind Hyg Occup Dis. 2020;38(0):E001

24. Lai J, Ma S, Wang Y, Cai Z, Hu J, Wei N, et al. Factors associated with mental health outcomes among health care workers exposed to coronavirus disease 2019. JAMA Netw Open. 2020;3(3):e203976.

25. Xiao H, Zhang Y, Kong D, Li S, Yang N. The effects of social support on sleep quality of medical staff treating patients with coronavirus disease 2019 (COVID-19) in January and February 2020 in China. Med Sci Monit. 2020;26:e923549

26. Cheng VCC, Wong S-C, Chen JHK, Yip CCY, Chuang WWM, Tsang OTY, et al. Escalating infection control response to the rapidly evolving epidemiology of the Coronavirus disease 2019 (COVID-19) due to SARS-CoV-2 in Hong Kong. Infect Control Hosp Epidemiol. 2020;5:1-6.

27. Liu M, He P, Liu HG, Wang XJ, Li FJ, Chen S, et al. Clinical characteristics of 30 medical workers infected with new coronavirus pneumonia. Chin J Tuberc Respir Dis. 2020:43(3):209-14.

28. Ng K, Poon BH, Kiat Puar TH, Shan Quah JL, Loh WJ, Wong YJ, et al. COVID19 and the Risk to Health Care Workers: A Case Report. Ann intern Med. 2020 Mar 16. https://doi.org/10.7326/L20-0175

29. Lan J, Song Z, Miao X, Li H, Li Y, Dong L, et al. Skin damage and the risk of infection among healthcare workers managing coronavirus disease-2019. J Am Acad Dermatol. 2020. https://doi.org/10.1016/j.jaad. 2020.03.014.

30. Remuzzi A, Remuzzi G. COVID-19 and Italy: what next? The Lancet. 2020 https://doi.org/10.1016/S0140-6736(20)30627-9.

31. Ebola Virus Disease in Health Care Workers — Guinea, 2014. https://www. cdc.gov/mmwr/preview/mmwrhtml/mm6438a6.htm. .

32. Senga M, Pringle K, Ramsay A, Brett-Major DM, Fowler RA, French I, et al. Factors underlying ebola virus infection among health workers, Kenema, Sierra Leone, 2014-2015. Clin Infect Dis. 2016;63(4):454-9.

33. Shalhoub S, Al-Hameed F, Mandourah Y, Balkhy HH, Al-Omari A, al Mekhlafi GA, et al. Critically ill healthcare workers with the middle east respiratory syndrome (MERS): A multicenter study. PLoS One. 2018 Nov 15;13(11): e0206831.
34. Chan-Yeung M. Severe acute respiratory syndrome (SARS) and healthcare workers. Vol. 10. Int J Occup Environ Health. 2004;10(4):421-7.

35. Health worker Ebola infections in Guinea, Liberia and Sierra Leone. https:// www.who.int/hrh/documents/21may2015_web_final.pdf. Accessed 10 Apr 2020

36. Zhou P, Huang Z, Xiao Y, Huang X, Fan X-G. Protecting Chinese healthcare workers while combating the 2019 novel coronavirus. Infect Control Hosp Epidemiol. 2020;5:1-4.

37. Evans DK, Goldstein M, Popova A. Health-care worker mortality and the legacy of the Ebola epidemic. Lancet Glob Health. 2015;3(8):e439-40.

38. Ji D, Ji Y-J, Duan X-Z, Li W-G, Sun Z-Q, Song X-A, et al. Prevalence of psychological symptoms among Ebola survivors and healthcare workers during the 2014-2015 Ebola outbreak in Sierra Leone: a cross-sectional study. Oncotarget. 2017;8(8):12784-91.

39. Abolfotouh MA, AlQarni AA, Al-Ghamdi SM, Salam M, Al-Assiri MH, Balkhy $\mathrm{HH}$. An assessment of the level of concern among hospital-based healthcare workers regarding MERS outbreaks in Saudi Arabia. BMC infect Dis. 2017;17(1):4.

40. Maunder RG, Lancee WJ, Balderson KE, Bennett JP, Borgundvaag B, Evans S, et al. Long-term psychological and occupational effects of providing hospital healthcare during SARS outbreak. Emerg Infect Dis. 2006;12(12): $1924-32$.

41. Maunder R, Hunter J, Vincent L, Bennett J, Peladeau N, Leszcz M, et al. The immediate psychological and occupational impact of the 2003 SARS outbreak in a teaching hospital. CMAJ. 2003;168(10):1245-51.

42. Selvaraj $\mathrm{SA}$, Lee KE, Harrell M, Ivanov I, Allegranzi B. Infection rates and risk factors for infection among health workers during ebola and Marburg virus outbreaks: a systematic review. J Infect Dis. 2018;218(suppl_5):S679-89.

\section{Publisher's Note}

Springer Nature remains neutral with regard to jurisdictional claims in published maps and institutional affiliations.

\section{Ready to submit your research? Choose BMC and benefit from:}

- fast, convenient online submission

- thorough peer review by experienced researchers in your field

- rapid publication on acceptance

- support for research data, including large and complex data types

- gold Open Access which fosters wider collaboration and increased citations

- maximum visibility for your research: over $100 \mathrm{M}$ website views per year

At BMC, research is always in progress.

Learn more biomedcentral.com/submissions 